\title{
Chapter 18: Developing Substitution Resources as Compensation for Reduced Groundwater Entitlements: The Case of the Poitou Marshes (France)
}

Olivier Douez1, Jean Eudes du Peuty 2, Daniel Lepercq 3 and Marielle Montginoul 4

1 BRGM (French Geological Survey), Bordeaux, France.

2 EPTB Marais Poitevin, Luçon, France

3 CACG, Tarbes, France

4 INRAE, UMR G-EAU, University of Montpellier, Montpellier, France

Corresponding author: O.douez@brgm.fr

Published in: Rinaudo, Holley, Montginoul \& Barnett (eds). 2020. Sustainable ground-water management: a comparative analysis of French and Australian policies and implication top other countries. Springer

\begin{abstract}
This chapter describes the groundwater management policy implemented in the Poitou marshes, a 100000 ha wetland located on the Atlantic coast in Western France. Similarly, to other French basins, irrigated agriculture has rapidly developed since the 1980's, mainly based on groundwater exploitation. Clear signs of groundwater overexploitation appeared in 1992-95, with the intrusion of brackish water in the aquifer. Because of the overexploitation, ecosystems were severely affected and the French Government was sued by the European Commission for non-compliance with the Bird Directive (1999). The chapter describes the progressive implementation of a groundwater management policy aiming at ensuring the long-term sustainability of an emblematic groundwater dependent wetland. To do so, the State imposed a very significant reduction in historical water entitlements. This case study illustrates the difficulties encountered in implementing this reduction, in a context of extreme competition between economic uses (agriculture, urban and touristic) and environmental objectives. The case study also reports on the complexity of developing an integrated management plan in basins where groundwater, rivers, wetlands and canals are highly interdependent. It highlights the importance of a (shared) knowledge on water resource and uses, of involving stakeholders in the different steps, and of trying to share scarcity in an equitable way.
\end{abstract}

Keywords: groundwater overexploitation, groundwater management, irrigation, wetland, hydrogeological model, substitution resources. 


\section{Introduction}

This chapter describes the groundwater management policy implemented for the Poitou Marshes, a 100,000 ha wetland located on the Atlantic coast in Western France. Just like other basins in central and western France (see chapter 5,13 ), irrigated agriculture has rapidly developed in this area since the 1980s, mainly based on groundwater extraction. Clear signs of groundwater overexploitation first appeared in 1992, with the intrusion of brackish water into the aquifer directly impacting some farmers as groundwater quality became unsuitable for irrigation. Ecosystems were also severely affected (with impacts on migratory birds) and the French government was sued by the European Commission for non-compliance with the Bird Directive (1999).

The chapter describes the progressive implementation of a groundwater management policy aiming at ensuring the long-term sustainability of an iconic groundwater-dependent wetland. To reach this environmental objective, the State has imposed a very significant reduction in historical water entitlements. This case study illustrates the difficulties encountered in implementing this reduction in a context of extreme competition between economic uses (agriculture, urban uses, and tourism) and environmental objectives. The case study also reports on the complexity of developing an integrated management plan in basins where groundwater, rivers, wetlands, and canals and highly interdependent.

The chapter is organized as follows: The first section presents the case study area, water resources and their uses. Section 2 describes the historical evolution of the quantitative management strategy progressively implemented in the Poitou Marshes. It ends by pointing out the process that took place to define the maximum volume to be abstracted. Section 3 depicts the groundwater model developed to assess sustainable pumping limits and define operational rules for refilling reservoirs. Section 4 focuses on the new established governance, looking in particular at the coordination between the State, the local water management board (EPMP - Etablissement Public du Marais Poitevin), and the users' associations. The last section concludes by analyzing the lessons learned from this experience in terms of the conditions for success and the limits of such a process for establishing quantitative groundwater management in agricultural areas. 


\section{The Case Study Area, Water Resources, and Their Uses}

The Poitou Marshes is the largest wetland on the Atlantic coast and is located halfway between the Loire and Gironde estuaries. It is the second largest in size in France behind the Camargue, and covers an area of 100,000 ha spanning three departments (Figure 1): Deux-Sèvres, Charente-Maritime, and Vendée. Its watershed basin extends over 640,000 ha.
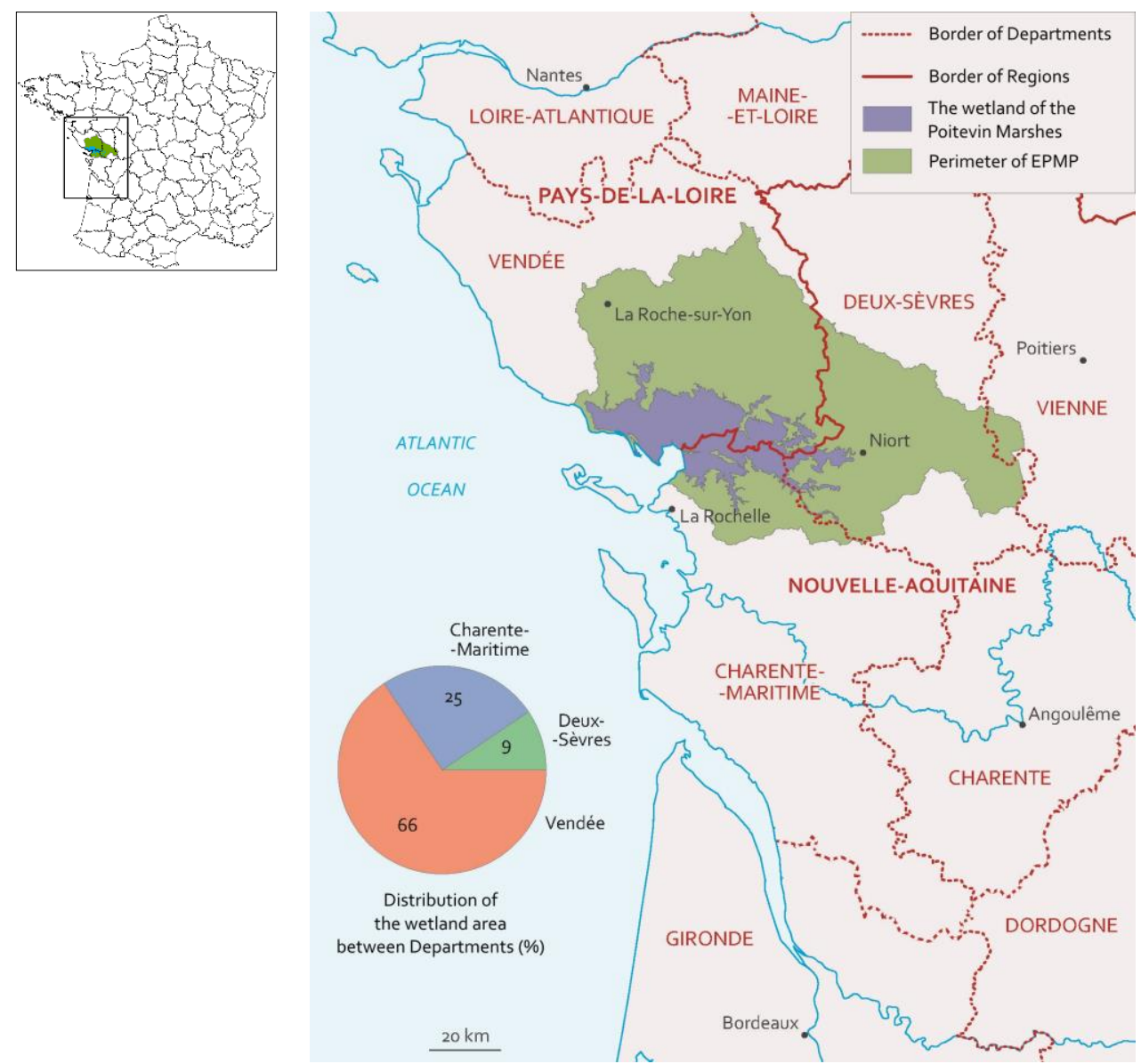

Figure 1. Location of the Poitou Marshes 


\subsection{A Unique Geological and Hydrogeological Context}

Located on the boundary between the Aquitaine Basin to the south and the Armorican Massif to the north, the area used to be a gulf that was progressively filled in by fluvio-marine clay called "Bri" during the socalled "Flandrian" transgression estimated to date back approximately 7,000 years (Anongba, 2007). The watershed basins that supply the Marshes with surface water spread over the Hercynian basement in the north, over the sedimentary terrain dating mainly back to the Lower (Toarcian) and Middle (Dogger) Jurassic in the east to the Seuil du Poitou, and over marly limestone terrain dating back to the Upper Jurassic in the south (Figure 2).

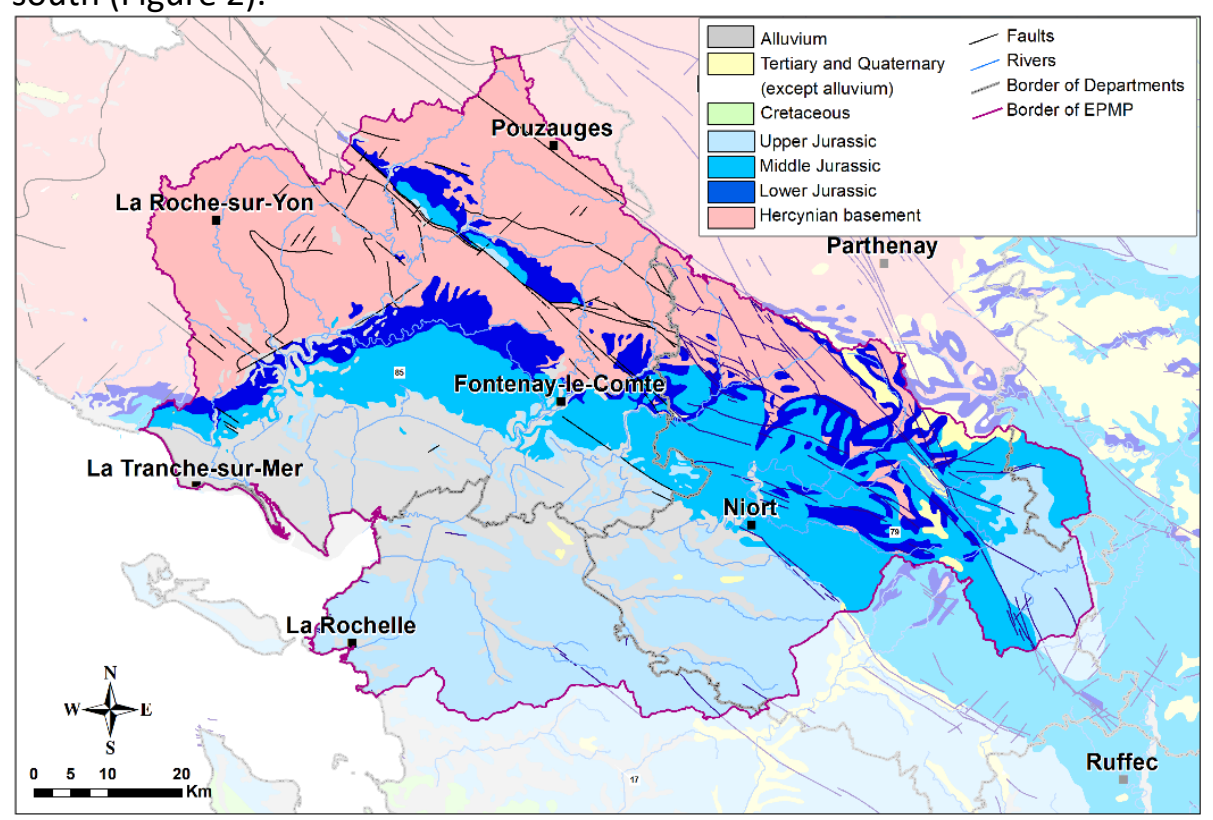

Figure 2. Geological Outcrop Formations on the Marsh Watershed Basin 


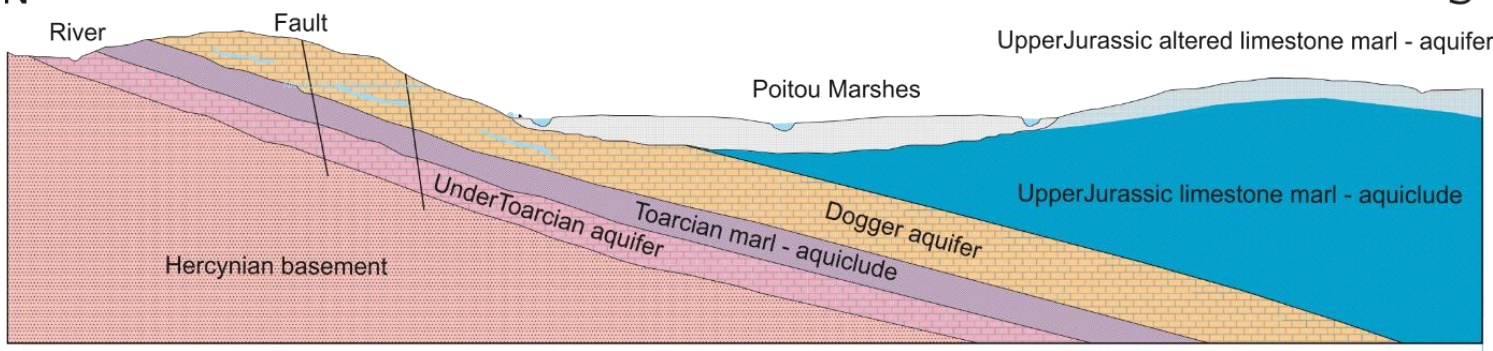

Figure 3. Schema Illustrating the Hydrogeologic Context of the Marshes - North-South Cross-Section

Three main aquifer formations occur in the study area: the Toarcian, Dogger, and Upper Jurassic, separated by low-permeable to impermeable aquicludes. The Dogger aquifer is the main water supply for the Marshes through discharge from overflow springs to the north and east.

Figure 3 presents a schematic cross-section of the aquifer formations in a north-south direction, showing the various stacked aquifers and aquicludes in the watershed basin.

The Poitou Marshes occupy the entire lower zone of the large depression (Figure 3). They are crossed by rivers (notably the Sèvre Niortaise), and form a complex environment where water plays a central role. While the Marshes themselves are underlain by a layer of rather impermeable clay, the surrounding altered, fractured or even karstic limestone units form good aquifers.

\subsection{The Development History of the Poitou Marshes}

The Poitou Marshes as they are known today have experienced strong human intervention mainly through many developments aiming to exploit the land, notably for farming. However, these developments made it necessary to manage flooding and the risks related to summer droughts.

Monks in the 8th century began draining the zone so that the wet soil could be cultivated. They built dikes and dug canals to grow crops on land that had until then been flooded. In the 17th century, Dutch investors developed most of the land that is currently cultivated, with the last polder taken from the sea in 1960. Later, lateral dikes along watercourses were built to prevent flooding during high flows. Indeed, crops in the 
Poitou Marshes have long depended on flooding. The first crops were market garden crops; then grains were grown in areas drained and protected by dikes and canals.

These developments led to the creation of two types of zones: wet marshes and dried marshes (Figure 4). Pastures are dominant in the wet marshes which serve as overflow basins during flooding, thus protecting the dried marshes which are used for larger crops.

Later, work was carried out to prevent sea water from encroaching during high tide, and then finally, sea dikes were built to protect the land from ocean storms.

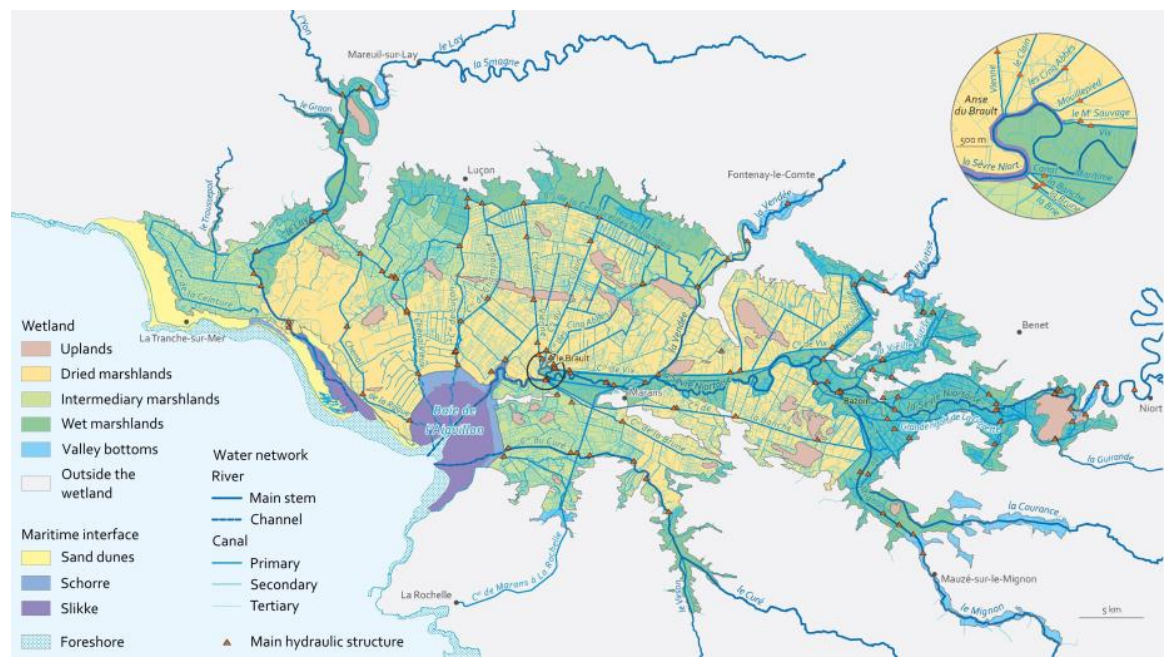

Figure 4. The Poitou Marshes Wetlands

\subsection{Water Use}

Currently, water from the Poitou Marshes watershed basin is used for three main purposes:

- Irrigation, now the main use for groundwater. In 2010, the volume of water taken was 77.9 million $\mathrm{m}^{3}$, with $67 \%$ coming from groundwater (Morardet and Boulfrad, 2013). In 2017, water abstraction authorizations were approximately 50 million $\mathrm{m}^{3}$ in the summer and 40 million $\mathrm{m}^{3}$ in the winter (inter-Prefecture decree of July 12, 2016) making it possible to irrigate approximately 25,000 ha from 1,500 
abstraction points throughout the watershed basin. While crop diversification is now considerable, irrigation of corn crops began in the 1980s. The climate is favorable for this crop, but the shallow and permeable soils require the regular addition of large amounts of water.

- Drinking water supply. The average annual abstraction for this purpose over the 2008-2011 period was approximately 50 million $\mathrm{m}^{3}$ of which more than 10 million $\mathrm{m}^{3}$ came from groundwater (information taken from the Loire Water Agency's database). In the Vendée Department, $90 \%$ comes from surface storages created for this purpose in response to the very sharp increase in demand during the summer tourist season along the coast.

- Aquaculture. The Bay of Aiguillon, the third largest mussel-growing area in France, is where fresh groundwater discharge (from overflow when groundwater levels are higher than the Marshes) mixes with sea water and provides essential nutrients for the growth of marine plants (notably plankton) on which mussels feed. This is one of the key requirements for shellfish development and therefore maintaining freshwater discharge during the summer low-water periods is important.

\subsection{The Southern Vendée, an Emblematic Sector}

Half of the surface area of the watershed basin for the Poitou Marshes is located in the Vendée Department (Figure 1). Because of its abundant water resources, it is the section of the study area that supports the largest users, with abstractions for irrigation authorized up to 25 million $\mathrm{m}^{3}$, or half of the total volume for the basin.

Since it is also the main area for supplying the Marshes, the environmental concerns are significant and led to the very early investment in water management. It was in this context that an original collective management system experiment was set up for irrigation extractions in one sector. This experiment is described in this next chapter.

\section{Implementation of Collective Water Management}




\subsection{The Irrigation Expansion Period and the First Problems}

In the 1980s, irrigation developed throughout France as it did in the southern Vendée, thanks to sizeable financial grants for drilling wells and installing pumps for individual use. This led to a growth in corn cropping that made it possible to stabilize and then expand an efficient agricultural economy.

But this greater demand for irrigation water lowered the groundwater levels in the southern Vendée. Regular monitoring of levels was thus initiated in 1987, with the progressive installation of additional reference piezometers managed by the Vendée Department.

The drought in 1990-1991 and the soaring demand for water that it caused highlighted the vulnerable nature of the resource. Agricultural abstractions caused groundwater levels to drop below sea level; the decline in the north of the Poitou Marshes caused a localized rise of connate salt water from the geological formations underlying the marsh (this salt is derived from sea water stored in the sediments that were deposited during the Flandrian transgression).

\subsection{2: First Steps in Collective Management}

Following those two difficult years, water stakeholders decided to set up collective management of water resources. The first summer abstraction management plan for agricultural use in the southern Vendée groundwaters was signed in 1992. It defined piezometric warning thresholds that triggered restrictions on abstractions and then their cessation, if they were exceeded. The objective was to prevent the overly rapid decline in groundwater levels through scheduled restrictions. In the event of threshold alerts, irrigation was first prohibited on Sundays, then Saturdays, and sometimes totally banned if the situation became too critical. ${ }^{1}$

\footnotetext{
1 The alert level corresponded to the lowest levels reached during the 1991 drought. In reality, the protocol allowed this threshold to be exceeded under certain conditions without triggering the total cessation of abstractions.
} 
The first reference piezometer used to define the thresholds was located at Oulmes in the Autizes sector (Figure 5). Indeed, this sector has always been the most fragile and most sensitive, being very close to the ecological and tourist heart of the Marshes known as the "Green Venice." Very rapidly, additional reference piezometers were selected and used either individually or by the averaging of readings from several of them. However, the minimum levels in the 1992 management plan were still below sea level and not sufficient to prevent salt water intrusion.

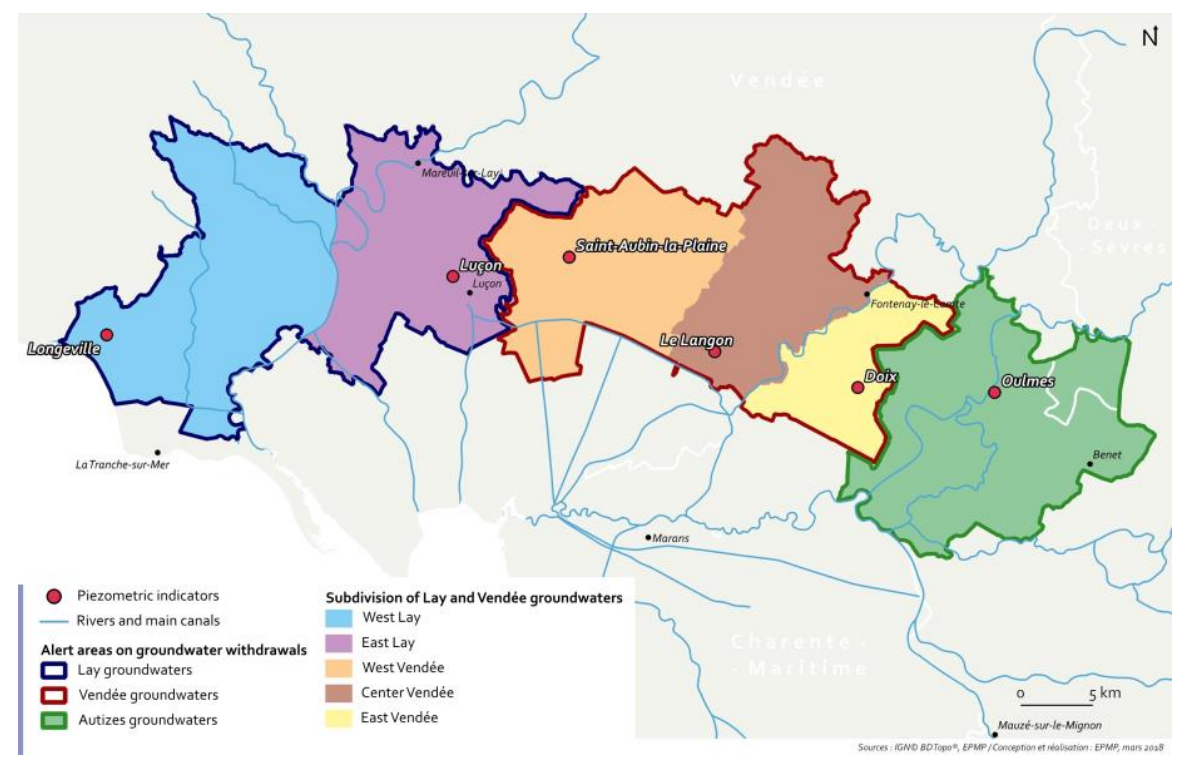

Figure 5. Southern Vendée Groundwaters with Warning Zones and Monitoring Indicators

Although this protocol was an important first step because it ended a situation in which abstractions were completely unlimited, the restriction schedules had a very limited and short-term effectiveness. Irrigation users became used to no longer irrigating on weekends and bought additional and more powerful pumps in order to be able to irrigate the same crop area in less time. The increased pumping infrastructure quickly cancelled out the effects of the restrictions, which as a result, became more frequent. A vicious circle thus began, leading to an overhaul of the management approach. 


\subsection{5: The Start of Collective Management Fully Involving Farmers}

The Water Law of 1992 set obligations that profoundly changed water management in the area (see Chapter 3). It became compulsory for irrigation users to measure their abstraction, which was a revolution that would make it possible to establish a collective management regime based on individual accountability.

In response to the difficulties being encountered, the farmers took control of their future in 1995 by grouping together (based on their type of water use) in irrigation users' associations to defend their interests.

The establishment of these associations made it possible to build dialogue between the association leaders, the State, and the departmental water management stakeholders, and was the start of collective management approach.

The State then initiated a new management model that sought to make each farmer individually accountable: The administration gave each user an individual authorization specifying the maximum volume that could be abstracted for the summer season. This volume was defined in a variable manner based on the demand and negotiations with each irrigation users' association:

- on the basis that one season corresponded to 1,000 hours of irrigation (about 42 days), the volume assigned was $1,000 \times$ pump capacity; or

- the volume depended on the requirement for the crops in question; or

- the volume was calculated based on a combination of the two previous methods, starting with pump capacity as the base and adjusting the results with a coefficient based on the crops in question.

This volume, which became a historic baseline, was itself based on equipment history. Even though a few spoke out to express their disagreement with these rules which some deemed unfair, they have not been challenged since.

The volumetric management regime covered the summer period only, with abstraction limits applied after June 1 . The goal was to encourage 
farmers to consume water earlier in spring to avoid overly large declines in groundwater levels during summer. Spring consumption was therefore initially not counted in these volumes. ${ }^{2}$ In the event of non-compliance with the warning levels in the month of June, the summer allocation was reduced. All consumption was declared by the irrigation users themselves at the end of the crop year; administrative verifications were rare and only targeted inconsistencies or doubts regarding declarations for past years.

In the event that summer consumption was higher than the overall authorized volume, the authorized volumes for the following year were reduced. Over-usage estimates were not done on individual farm level, but rather collectively, with the application of a reduction coefficient to the sum of authorized volumes (i.e. a collective penalty). This system was a first step toward volumetric management. However, it made those extracting water only moderately accountable, as they did not know the results of their actions until after the end of the irrigation season when all abstractions were known. This system was then overhauled to progressively include individual accountability.

\subsection{Recent Evolution: Toward a Suppression of the Structural Deficit}

Extreme weather events then drove changes in the management approach. The 2003 drought led to the realization that such crisis situations need to be anticipated and planned for, and made it possible to generalize framework agreements which define responsive measures for these exceptional situations. Henceforth every year before the start of the irrigation season, a Prefectoral Decree defines the crisis response measures which include restricting use and protecting priority uses.

Progressively, it was noted that the effort was to move from crisis management to management of a structural shortfall in the water

\footnotetext{
${ }^{2}$ Starting in 2005 , spring consumption was also limited because the management regime had led to an improvement in summer conditions by shifting the overextraction problem to the spring.
} 
balance. The aim was to secure drinking water extractions, and meet the needs of environmental and economic uses (including agriculture) in 8 out of 10 years and reach the 'right water status' by 2021 . Thus, the water resource must be the subject of balanced quantitative management and crisis management modes were only to be mobilized during exceptional climate episodes.

All this was given concrete form in planning documents (the SDAGE on the regional level, and SAGEs on the level of the watershed basin). These documents defined groundwater level targets that were sufficiently high enough to ensure good water supply to the Marshes in all seasons. The threshold for the start of the low-water period was therefore set to allow considerable supply in the spring at a time when the risk for biodiversity is at its maximum; the threshold for the end of the low-water period sought to guarantee a minimal level higher than that of the marsh to avoid any saltwater intrusion. The principle was to define ambitious target levels with a lengthy delay for their application (some indicators were thus set for compliance as early as 2021, and others only after 2021).

After 2000, this principle sparked extensive debate with numerous studies carried out that were for or against, the ambitious target levels. Ultimately, BRGM was called upon to develop a groundwater flow model that would provide better understanding of how the aquifer system worked.

To prevent significant reductions in authorized volumes, irrigation users' associations mobilized to generate substitution reservoir projects. The substitution principle consists of filling surface reservoirs by pumping groundwater in winter when piezometric levels are high. The stored water is then used later in the summer, making it possible to reduce groundwater abstractions during this period.

In the southern part of the Vendée Department, the first reservoirs were built under the management of an inter-communal joint association (SMVSA) and commenced operation in 2007 (Table 1). SMVSA entrusted reservoir management to a manager (the CACG - Compagnie d'Aménagement des Coteaux de Gascogne). 


\begin{tabular}{|l|c|c|}
\hline Sector & $\begin{array}{c}\text { Number of Reservoirs } \\
\text { Created / Planned }\end{array}$ & $\begin{array}{c}\text { Storage (in million } \mathrm{m}^{3} \text { ) } \\
\text { Created / Planned }\end{array}$ \\
\hline Autizes & $10 / 10$ & $3.2 / 3.2$ \\
\hline Vendée & $8 / 10$ & $4.4 / 5.4$ \\
\hline Lay & $4 / 5$ & $1.75 / 2.4$ \\
\hline
\end{tabular}

Table 1. Number of Reserves and Storage Levels Produced as at January, 2018

In this context of a highly variable climate and rather dry periods in 2016 or very dry periods in 2017 (with little or no groundwater recharge), the building of the first reservoirs made it possible to relieve water stress on the environment. A $3 \mathrm{~m}$ rise in groundwater levels was noted in Oulmes to the east, and a $1 \mathrm{~m}$ rise in Saint Aubin in the center and Luçon further to the east. These levels stayed above or near the target piezometric levels.

\subsection{The Effectiveness of Management Measures}

The establishment of quantitative management made it possible to progressively reduce the magnitude of the summer decline in groundwater levels. Figure 6 shows the evolution of measured levels over several years. In 1990 before abstractions were limited, the level dropped rapidly between April and August, with warning thresholds being passed on July 15 and the end-of-season level being $0.5 \mathrm{~m}$ below sea level. The situation improved in 1995 and 2005, clearly showing the temporary effect of scheduled restrictions with a small rise in groundwaters on days when abstractions were banned (resulting in a saw-tooth curve). However, the end-of-season levels remained very low. Eventually, the level recovered above the warning threshold in 2010 and 2015. 


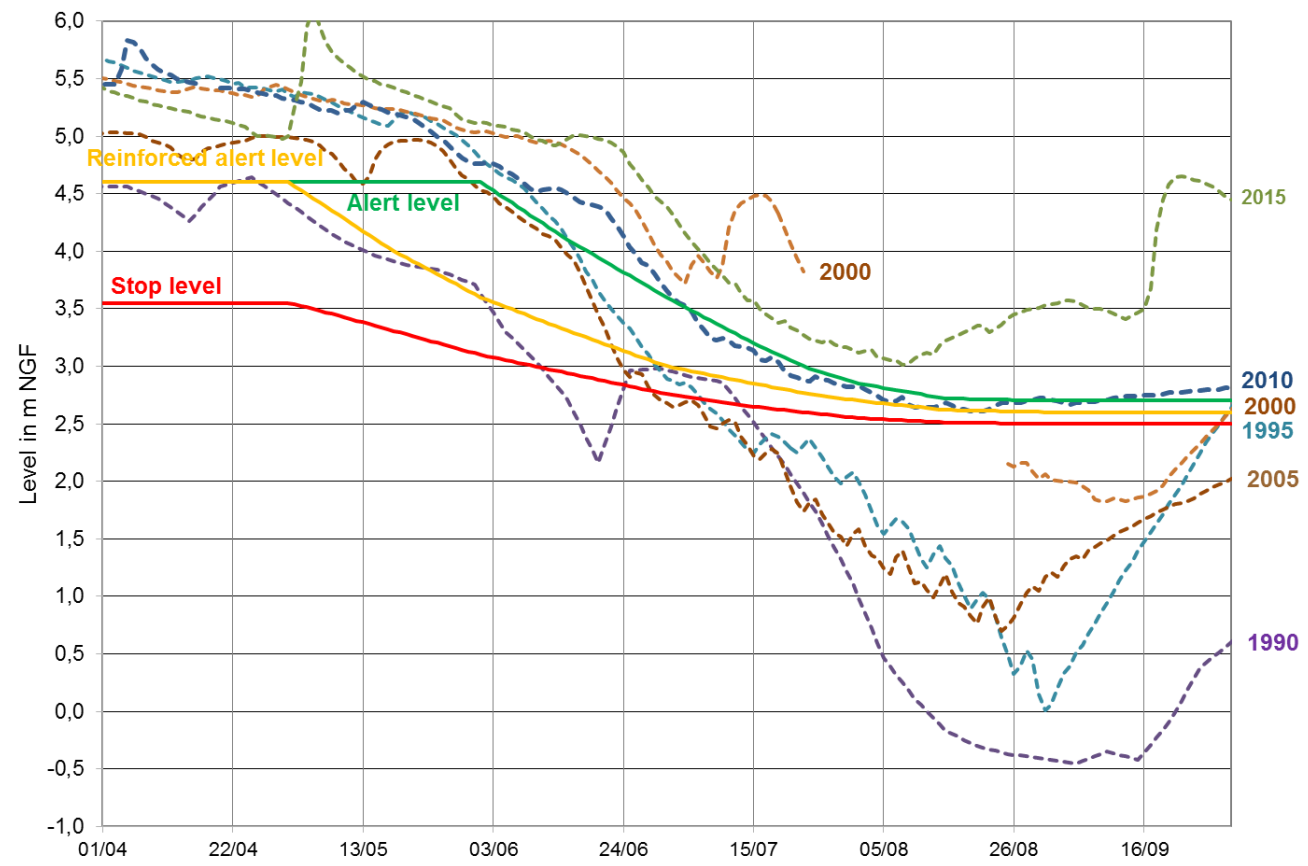

Figure 6. Historical Groundwater Levels

\section{The Groundwater Model Developed to Improve Knowledge, Assist Management, and Guide Investments}

Setting up the previously described management required improving knowledge of how aquifers function, and their interactions with surface water. This knowledge acquisition process was initiated at the end of the 1980 s with the installation of the first piezometers. A modeling tool was then developed in 2007 at the request of the State to assist in the calculation of the volumes authorized for abstraction. As a result, the Jurassic hydrogeologic model (Putot and Bichot, 2007) was adopted on this sector (Douez, 2010; Douez et al., 2010) and was subsequently updated following various investigations (Douez et al., 2011; Douez, 2015; Douez, 2015), in partnership with stakeholders in the field, and notably with the Poitou Marshes Public Establishment (EPMP). 
This model is a response to the need to have a water resource management tool integrating all watershed basins and in particular those supplying the Marshes. It is part of the set of tools developed in the westsouthwest of France to help manage groundwater on a regional scale (Douez et al., 2016; Wuilleumier et al., 2016), with the aim to:

- better understand the operation of all aquifer formations and, for some, analyze groundwater/river relationships; and

- help answer various questions relating to water resource issues such as availability, management, impact of global warming, etc.

\subsection{Presentation of the Hydrogeologic Model}

The modelling code used in this model is MARTHE ${ }^{3}$ developed by the BRGM (Thiéry, 2015). The Jurassic regional hydrogeologic model is calibrated over the 2000-2011 period on a monthly and weekly time scale (June to August). It covers a surface area of $20,195 \mathrm{~km}^{2}$ (Douez, 2015). The model has a $1 \mathrm{~km}$ grid size, except in the northern periphery of the Poitou Marshes where the grid size is $333 \mathrm{~m}$ in order to better represent the interaction with waterways and abstraction zoning. It contains eight layers corresponding to the various aquifers and aquitard layers in the area.

The groundwater recharge calculations for the entire surface area of the model were based on hydro-climatic balance sheets (a breakdown of recharge and runoff) drawn up from spatialized evapotranspiration data and rainfall.

Since groundwater/river exchanges play an important role in regional water dynamics, the main waterways were included in the model. Abstractions and discharge of water, either for groundwater or surface water, were integrated for the 2000 to 2011 period (abstractions for drinking water supply, agriculture and industry, as well as discharge from

\footnotetext{
${ }^{3}$ MARTHE: Modélisation d'Aquifères par un maillage Rectangulaire en régime Transitoire pour le calcul Hydrodynamique des Ecoulements (modeling of aquifers in rectangular grids in the transitional regime for the hydrodynamic calculation of groundwater flows).
} 
wastewater treatment plants). Seven dams (low flow support, drinking water supply, etc.), located along waterways, were also considered. ${ }^{4}$

\subsection{Uses of the Model to Manage the Marshes}

\section{7-2010. First Use of the Model to Manage Groundwater in the Poitou Marsh Sector}

The model (assuming conditions experienced during the 2000-2007 period) made it possible to test various agricultural abstraction reduction scenarios (Douez et al., 2010). This reduction was first simulated by applying single reduction coefficients to the total annual volumes extracted, and then by differentiating the spring and summer reduction. This made it possible to calculate an extractable volume based on targets for groundwater levels and waterway flows (the volume extracted that would enable the targets to be met in 8 years out of 10 ).

\section{1-2016. Simulations of Establishing Substitution Reservoirs}

Following this work, and based on the extractions volume limits set in 2010, the model was used to test different scenarios for the establishment of reservoirs to substitute groundwater abstractions in the Lay (Douez, 2011), Vendée (Douez, 2012), and Sèvre-Niortaise (Abasq, 2016) sectors.

The analysis of the simulation results indicated that setting up substitution reservoirs would greatly improve the summer piezometric levels as well as the flow in waterways throughout the study zone. The simulations also predicted it would be possible to comply with most of the piezometric targets set in the SDAGE. The negative impact during the winter reservoir filling period was low compared to a very significant positive impact in summer for both groundwater and surface water supplies in the Marshes when the supply from reservoirs replace extraction from boreholes.

\footnotetext{
${ }^{4}$ It should be stated that the model for the Poitevin Marshes does not aim to simulate the hydraulic behavior of the "marsh" zone (i.e. flows in canals) where the manipulated hydraulic operation are complex.
} 


\section{The Reduction of Entitlements}

The model simulations performed also made it possible to determine the volumes that could be extracted in order to attain the piezometric level targets for the management zone. These volumes were generally much lower than current abstractions.

\subsection{Reduction process}

The authorized volume over the entire territory for the spring-summer period needed to fall from 49.6 to 32 million $\mathrm{m}^{3}$. This structural reduction was obtained in part, by a reduction in volume (by a minimum of $20 \%$ ) without compensation, and in part by the water source substitution programs which had the greatest impact on the environment.

Once the overall limit had been set, the maximum annual authorized volumes were divided among irrigation users by sector, by abstraction installation, and by period. The volume assigned annually per installation depended on demand, past consumption and the impact of the abstraction. Volumes freed up by an irrigation user ceasing irrigation were allocated as a priority to new irrigation users, and then to increasing volumes for existing users.

The distribution plan was drawn up by the structure chosen to lead this task as "Organisme Unique de Gestion Collective" (OUGC - collective water management board): the EPMP. To do it, the EPMP collaborated with irrigation user representatives, owners, and the managers of substitution infrastructures. This distribution plan was adjusted annually to take into account any new reservoirs built and abstraction reduction targets in zones where the extractable limits were lower than actual abstractions. In this way, it was possible to accompany the abstraction reductions in these challenged zones with the redistribution of available water to new irrigation users.

\subsection{Temporal and Operational Management}

After abstraction reductions and reservoir capacities were considered, the extractable volume limits that were set aimed to reduce the structural deficit between actual extractions and the authorized volume limit over 
the entire territory. Compliance with them did not however, guarantee that the 'right ecological state' of water resources and the environment would systematically be achieved every year. To account for climatic variations, a series of operational management rules was established and set up for each management sector.

These operational management rules covered zones with collective and pooled management in which all irrigation users contributed to lowering the level of abstractions in summer low-water periods.

At the end of May, each irrigation user indicated the projected distribution of their authorized volume based on their projected needs for their crops. This distribution would define the management rules to which each user would be subject during the irrigation season.

During the season, the volume could be reduced based on changes in groundwater levels with reference to a management curve called the warning threshold, which considered target piezometric levels for the start of the low-water period as well as the natural discharge of groundwaters.

- If the groundwater level was above the warning curve, consumption was not limited.

- If the groundwater level was located between the warning curve and the heightened warning level, the volume for the fortnight could be reduced by up to $50 \%$.

- If the groundwater level fell below the heightened warning threshold, the volume was reduced by at least $50 \%$.

- Finally, as soon as the stoppage level was crossed, irrigation was banned ${ }^{5}$.

Each management zone was monitored daily by at least one reference piezometer (Figure 7). A public application was set up by the EPMP to allow monitoring: the Système d'Information de l'Eau sur le Marais Poitevin (SIEMP, or Poitou Marsh Water Information System).

${ }^{5}$ The OUGC was in charge of system management so long as the groundwater levels were above the heightened warning threshold; below that level, the State intervened (Figure 6). 


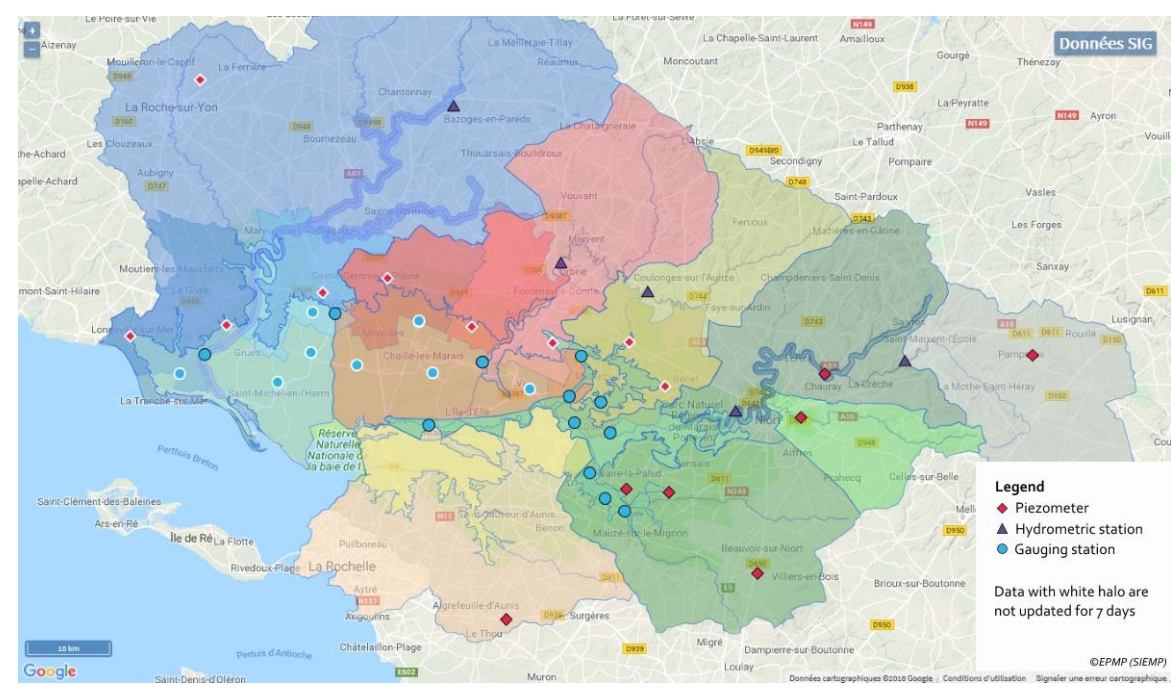

Figure 7. Location of Reference Piezometers to Monitor Water Volumes

As soon as stress on the resource was detected during the irrigation period, a management committee would meet every fifteen days. Chaired by the EPMP and assisted by its manager, it brought together representatives of the administration, the agricultural industry and the irrigation users' association. After consultation, it decided on the appropriate limits required to maintain the target groundwater levels by using predictions from the groundwater model which used knowledge of future crop needs, upcoming weather, observed groundwater levels and the monitored consumption in real time as inputs.

\subsection{Water Management Based on Unity Among All Irrigation Users on Sector Scale}

The novelty of the new management approach was to create unity among all water extractors in a given management sector. The same management rules applied to all, whether or not they were connected to a substitution reservoir. This took form in two ways: firstly, a single water tariff was established, whereby investment costs for the reservoirs (part of which was not subsidized by the State) and all operational costs were thus shared among all users. Secondly, all water users were subject to the same management rules. This volumetric management was applied to 
three sectors in the southern Vendée, starting in 2006. If the groundwater level fell too rapidly, volumetric restrictions were applied to all users, even those connected to a reservoir storage. This principle of sharing both the costs and benefits of reservoir substitution was a key factor in the success of the operation through the social ties it developed. In order to prevent opportunistic breaches of the restrictions, the management system included sanction and verification measures:

- Individual over-usage of the authorized volume was penalised by a minimum of an equivalent reduction the following year. Over the entire South Vendée sector, a financial penalty for excess use on a fortnightly basis as well as the total volume over the irrigation season, resulted in a considerable reduction in individual over-usage.

- The CACG set up a random enhanced verification system to ensure the proper reading of all meters every fortnight. Later, abstraction points were progressively equipped with smart meters (that can be read remotely by telemetry) that made it possible to obtain data on a daily basis automatically.

Figure 8 shows the effectiveness of the management approach by comparing the average water levels during the summer low-water period before the implementation of the governance system in 2012, to those measured after 2012.

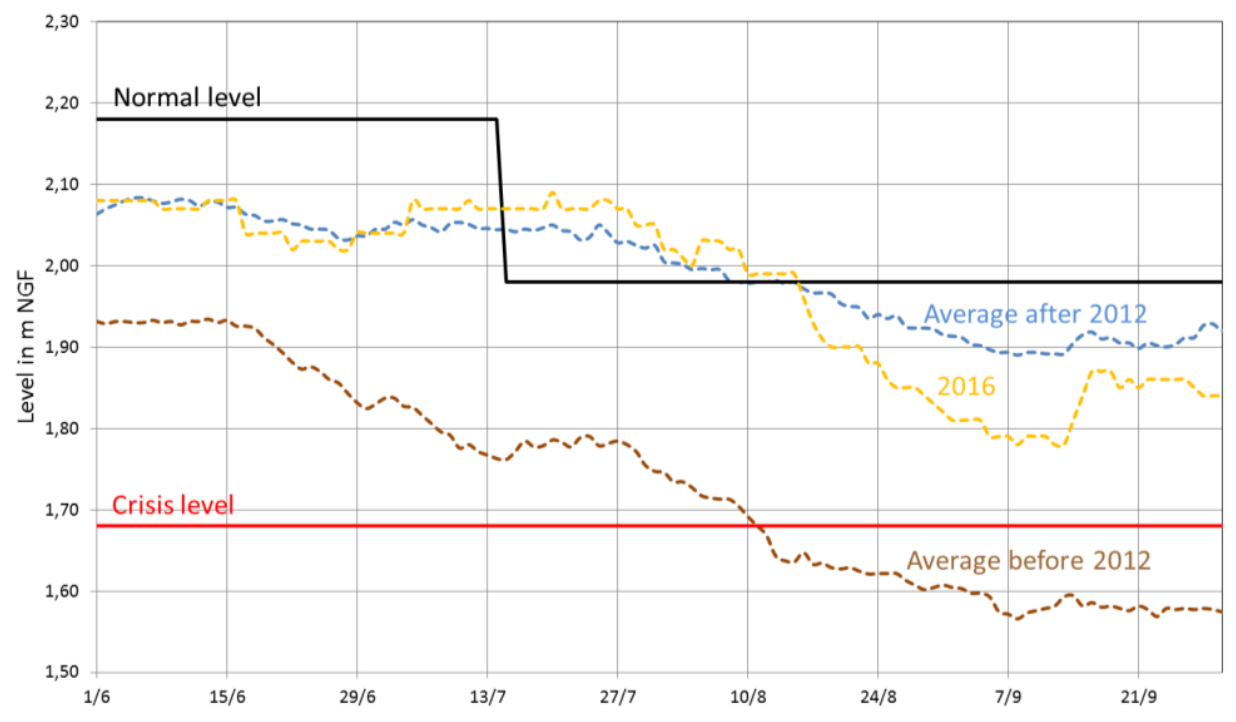


Figure 8. Comparison of Water Levels at Saint Arnault Before and After Implementation of the New Water Governance System

\subsection{Governance Report by a Non-Agricultural OUGC}

There are two main contributing factors to the farmers' acceptance of the management measures that were implemented. Firstly, various hydrogeological experts and the groundwater model helped them understand how groundwater system worked, in particular how abstractions downstream were influenced by those carried out upstream. In addition, although the planning documents (SDAGE) forced a reduction in extracted volumes to the extractable volume limit, the establishment of substitution reservoirs allowed them to maintain their irrigation potential.

The choice of substitution zones was not made by the irrigation users but was determined through use of the groundwater model. The quality of the modeling was acknowledged by agricultural bodies, reservoir project implementers, nature forecasting associations, and the EPMP. This helped make irrigation users confident in their decision to accept the substitution reservoirs as a replacement for their individual boreholes. The reservoir project implementation was driven by local territorial governments and not by agricultural bodies. This provided an additional guarantee that the substitution was not done to favor any given group of water users. The neutrality of the expertise of the public service delegate (the CACG) also helped with project implementation.

For its part, the EPMP obtained management autonomy from the State provided that a protocol for managing and monitoring consumption was established. Such a protocol would be only accepted if:

- The limits had a visible and predictable effect on monitoring indicators. Analysis of changes in groundwater in relation to changes in consumption was therefore vital.

- The information was widely shared. The EPMP met every two weeks with all stakeholders to analyze the information and propose appropriate management actions. These decisions were made collectively. During this process, the importance of irrigation users' representatives on this management committee must be emphasized 
as they played a vital role in relaying information to all irrigation users in the field.

- The volumes abstracted were metered and verified. Since the accuracy of the analysis of the effect of abstractions on groundwater levels was crucial, reliable monitoring and verification of abstractions needed to be established. This was done by installing water meters, by obliging all irrigation users to report their own consumption every 15 days, and finally by installing smart meters. Indeed, the verifications showed some discrepancies between the declarations and the actual volumes extracted; smart meter readings introduced transparency and equal treatment for all, even though it felt intrusive to some.

- Conflict was reduced. Established in 2012, the EPMP was able to establish respect and authority with stakeholders by assuring all users that the collective, shared management regime in place sought to respect extractable volume limits and if implemented well, would allow everyone to irrigate with a minimum of restrictions. One group could not gain precedence over another; and that in the event of management failure, the State would intervene and there would be a risk of a sharp reduction in authorized abstractions.

The creation of substitution reservoirs did not happen smoothly. The wider community was opposed to it, and environmental associations filed legal action against the first authorization decree. Here, it should be noted that this system for southern Vendée, which was based on setting up clear management rules and monitoring and verification of abstractions, allowed two other projects (Vendée and Lay) to be accepted without contest later. The relevance of the analysis and information sharing allowed increasingly smooth governance in this territory and the reconciliation of the quantitative water balance target for biodiversity and the preservation of effective agricultural activity.

\section{Lessons learnt from Experience}

The Poitou Marshes experiences very unique interactions between surface water and groundwater resources that contribute to the development of an ecosystem with a rich diversity of flora and fauna. The 
marshes can be subdivided into two broad areas; the older marsh supply upstream zone that has been drained and where water extraction occurs for irrigation and drinking water supplies, and the marsh itself which is a living environment downstream for flora and fauna, pastures and leisure. The marshes are therefore divided into two zones which have different water uses and stakeholders. This situation complicated the establishment of the management regime that relied on both groups of water users being aware of connectivity between their water resources and required those located in the supply zone to accept restriction measures that did not provide them any benefits.

The success of the novel water management approach described in this case study can be contributed to many factors, the most important of which are summarized below:

- Unity among irrigation users, irrespective of the source of the water they use (waterways, groundwater or reservoirs). This unity is seen in the willingness to pay for infrastructure even among those who do not benefit from it directly, and acceptance of restrictions on abstractions even when their resource is not directly affected by overuse.

- A shared effort to attain the allowed agricultural abstraction volume limit, through demand reduction (water saving) measures and the creation of substitution reservoirs that have minimal impact on the resource condition because they are filled outside of the high demand period.

- Spatial management of restrictions based on the impact of abstractions. These restrictions were also scaled to individual circumstances previously declared by each farmer in order to impact them as "fairly" as possible, by considering their actual needs.

- Management carried by a non-agricultural body with the aim of seeking cooperation among the various stakeholders. This body was also entrusted with allocating the maximum volume able to be extracted for agriculture amongst farmers. But it entrusted enforcement of measures to a manager used to sharing water among farmers (the CACG). 
- Excellent knowledge of the resource and the use of the water. This made it possible to manage the resource for the best outcomes, gain acceptance for the measures taken, and optimize structural investments (for example, the size and location of substitution reservoirs). This knowledge was widely shared via a website. This allowed all stakeholders to be informed of management decisions, and potentially be able to provide feedback on the proposals.

- An information system on agricultural abstraction volumes that made it possible to guarantee and verify enforcement of restriction measures.

- A double sanction system. Both financial and volumetric penalties encourage compliance with restriction measures.

- Reactive joint management. Bimonthly meetings of a management committee are held as soon as adverse resource trends are detected which allow stakeholders to decide collectively on the adoption of appropriate restriction measures and to inform users.

This success can also be explained by more practical elements: management decisions relayed to water users in the field by the farmers' representatives, a non-agricultural management body in which all stakeholders placed their trust, and an early awareness of potential crisis situations.

However, certain tensions remain as the wider community did not easily accept the creation of substitution reservoirs. The balance that has been achieved is fragile and could be threatened if there are considerable modifications of the targets for the groundwater and extraction levels in future planning documents.

\section{Bibliography}

Abasq L. Simulation de l'impact des projets de réserves de substitution du bassin de la Sèvre Niortaise/Marais poitevin avec le modèle hydrodynamique du Jurassique - Phase 2. Brgm, Rapport final BRGM/RC65669-FR, 2016, 159 p., 
Anongba B. Identification du système hydrogéologique des formations quaternaires et callovo-oxfordiennes du Marais poitevin par approche couplée minéralogique, hydrodynamique et géochimique. 2007, 1 vol. (379 p.) p.,

Douez 0 . Apports des modèles hydrodynamiques régionaux pour contribuer à la gestion des ressources en eaux souterraines : exemple du modèle Jurassique du Poitou-Charentes pour le Marais poitevin. Toulouse, 25-27 novembre 2010, p.

Douez O. Simulation de l'impact des projets de réserves de substitution du secteur du Lay avec le modèle hydrodynamique du Jurassique. Brgm, BRGM/RP-60122-FR, 2011, 85 p.,

Douez O. Simulation de l'impact des projets de réserves de substitution du secteur Vendée avec le modèle hydrodynamique du Jurassique simulations complémentaires. Brgm, Rapport final BRGM/RP-60956-FR, 2012, 139 p.,

Douez O. Actualisation 2008-2011 du modèle maillé des aquifères du Jurassique. Brgm, Rapport final BRGM/RP-64816-FR, 2015, 209 p.,

Douez O. Mise au point d'un outil pour la gestion des autorisations de prélèvements annuelles de l'EPMP. Brgm, BRGM/RP-65052-FR, 2015, 108 p.,

Douez O., Bichot F., Dequidt D., Dugrillon D., Putot E. et Petit L. Contribution à la gestion des prélèvements à la périphérie du Marais poitevin par modélisation hydrodynamique. BRGM/RP-58297-FR, 2010, $239 \mathrm{p.}$

Douez O., Bichot F. et Petit L. Contribution à la gestion quantitative des ressources en eau à l'aide du modèle Jurassique de Poitou-Charentes. Brgm, BRGM/RP-59288-FR, 2011, 411 p.,

Douez O., Cabaret O., Saltel M., Abasq L., Wuilleumier A. et Pedron N. Groundwater management of large aquifers in southwestern France by regional hydrodynamic models. Montpellier, France, 25-29 septembre 2016, p.,

Morardet S. et Boulfrad Y. Etat des lieux de l'agriculture irriguée dans le Marais Poitevin. Irstea, 2013, 117 p.,

Putot E. et Bichot F. CPER 2000-2006 Phase 4 - Modèle Infra-Toarcien Dogger : calage du modèle hydrodynamique en régime transitoire. Brgm, BRGM/RP- 55742-FR, 2007, 94 p., 
Thiéry D. Code de calcul MARTHE - Modélisation 3D des écoulements dans les hydrosystèmes - Notice d'utilisation de la version 7.5. Brgm, BRGM/RP64554-FR, 2015, 308 p.,

Wuilleumier A., Saltel M., Douez O., Cabaret O., Abasq L. et Pedron N. A platform to harmonize the regional hydrodynamic models in the southwest of France. Montpellier, France, 25-29 septembre 2016, p., 